\title{
Enseñar, prioridad revolucionaria
}

\author{
Salvador Camacho Sandoval / Marcelo Hernández. Santos
}

Marcelo Hernández Santos (MHS): El centenario de la revolución resultó un buen motivo para reflexionar sobre este acontecimiento nacional y su relación con la educación. Mucho se ha discutido al respecto, hay tesis que sostienen que la Revolución Mexicana no fue un movimiento verdaderamente popular, donde los campesinos fueron los protagonistas principales. De acuerdo con su experiencia como historiador de la educación en México, ¿cuál sería su concepción de lo ocurrido en el período de 1910-1917?

Salvador Camacho Sandoval (SCS): La llamada Revolución Mexicana fue un gran movimiento social que tuvo una complejidad tal que aún nos ocupa a los académicos y no académicos para comprender sus causas, propósitos, naturaleza y resultados. Fue la primera gran movilización del siglo XX y su intensidad e impacto trascendió fronteras. En la Revolución Rusa, en las propuestas de los republicanos en España y en importantes organizaciones liberales y de izquierda en países de América Latina, se escucharon los ecos de lo que se inició en México en 1910, hace exactamente una centuria.

A antes aparecían nublosos. Ahora sabemos que la Revolución tuvo un carácter popular, campesino y nacionalista, tal como lo señaló Tannenbaum y lo retomó y argumentó décadas después con una magnífica investigación el inglés Alan Knight; pero también ahora sabemos que hubo diversos intereses que jugaron un papel muy importante en el rumbo que siguió el movimiento. En primer lugar, destacaría la intervención de los grupos poderosos de exporfiristas que abogaban por un país moderno y democrático. Recordemos que Francisco I. Madero pertenecía a los hacendados norteños que estando en la presidencia no cumplió con las demandas de los campesinos liderados por Emiliano Zapata.

Otros grupos importantes fueron los ilustrados de clase media, algunos de los cuales se radicalizaron y asumieron ideas anarquistas y socialistas, para lo cual concibieron que concientizar y organizar a la clase obrera mexicana, aún sin mayor fortaleza social y política, era una necesidad para darle a México un rumbo realmente revolucionario, donde la clase proletaria fuera vanguardia de la transformación profunda del país. De este grupo yo resaltaría, sin lugar a dudas, a los hermanos Flores Magón y su proyecto cultural y educativo.




MHS: ¿Y qué me puede decir del protagonismo de los obreros y campesinos, y las propuestas encontradas de los grupos revolucionarios?

SCS: Como sabemos ahora, no fueron los obreros sino los campesinos los que marcaron un rumbo importante al movimiento revolucionario. Las presencias de Francisco Villa y sobre todo de Emiliano Zapata dieron el perfil de un movimiento vinculado a las demandas por la tierra, más que por la democracia y medidas de otra naturaleza. En este punto, la discusión se ha centrado en si dichos campesinos fueron usados 0 realmente fueron protagonistas del cambio. Según mi punto de vista, fueron las dos cosas, porque la Revolución fue un movimiento que despertó ambiciones de caciques locales que se opusieron a medidas nacionales que se estaban tomando desde el centro y que violentaban su poderío en la región. El caso de Saturnino Cedillo en San Luis Potosí es un ejemplo claro de ello. Las historiadoras Romana Falcón y Beatriz Rojas han hecho estudios sobre el particular.

El llamado grupo sonorense fue finalmente el que se benefició con todo esto. Álvaro Obregón, primero, y Plutarco Elías Calles, después, como presidentes de la República, institucionalizaron la Revolución e iniciaron una etapa de modernización del país, reconstruyendo el Estado, impulsando reformas y dando cabida a procesos nuevos de participación. Todo ello, sin embargo, sin retomar procesos democráticos y permitiendo la conformación de nuevas élites que se movían muchas veces por encima de los intereses nacionales y en contra de los ideales revolucionarios. De aquí surgió toda una leyenda negra de políticos corruptos y oportunistas de los que las novelas, más que la historia académica, nos dan mejor cuenta. Allí está La sombra del caudillo, de Martín Luis Guzmán.

MHS: De todo esto ¿cuáles fueron las aportaciones fundamentales de este movimiento a la nación mexicana?

SCS: La Revolución sí trajo cambios en la política, pues logró derrotar y desplazar a la antigua élite porfirista. En materia de desarrollo económico, inicialmente la Revolución provocó el caos y más adelante retomó el impulso modernizador porfirista desde otro contexto y con un planteamiento nacionalista, aquí faltó un cambo radical, tal como algunos lo exigían, sobre todo, para que se beneficiara la población mayoritaria y pobre de México. En el aspecto cultural yo creo que hubo un impulso a la educación, con el propósito de formar ciudadanos que respondieran a las nuevas exigencias del país. Al mismo tiempo, se vio como un derecho que no todos disfrutaban, pues el porcentaje de analfabetismo entre la población era realmente alarmante.

MHS: La educación de masas, cuyas características principales obedecieron a las tesis del Ministro de Instrucción Pública francés, Jules Ferry: laicidad, gratuidad y obligatoriedad, fue un precepto legal existente desde la Constitución de 1857; sin embargo, su concreción en los años posteriores a la segunda mitad del siglo XIX y específicamente durante el Porfiriato, es discutible, ¿usted considera que la Revolución Mexicana logró resarcir esta deuda con las clases populares? ¿En qué 
momento del auge revolucionario se planteó con nitidez esta aspiración popular? ¿El proyecto educativo de la Revolución fue muy distinto al iniciado por Justo Sierra a finales del régimen porfirista?

SCS: Ciertamente las ideas de ofrecer una educación laica, gratuita y obligatoria vienen desde décadas atrás a la Constitución de 1857 y después a la de 1917, y se discutían en otros países, no sólo en Francia. También es verdad que la propuesta revolucionaria de educación, sobre todo a partir del proyecto de la Secretaría de Educación Pública (SEP) que encabezó José Vasconcelos, recogía lo que Justo Sierra había hecho como responsable de la educación durante el Porfiriato. El mismo Sierra había sido maestro de Vasconcelos. La diferencia está en su proyección popular en términos cuantitativos y en sus contenidos; es decir, los grupos revolucionarios vieron a la educación como prioridad, desde los maderistas a los magonistas y de los carrancistas a los zapatistas. A partir de la creación de la SEP, en 1921, se inició una reforma educativa sin precedentes. Enseñar a leer y escribir fue una exigencia básica, para lo cual los maestros fueron clave, la columna vertebral de lo que vendría a constituir el factor detonador de un movimiento cultural en el campo mexicano. Los profesores rurales, además de enseñar la lectoescritura, favorecieron cambios en la mentalidad de niños y adultos. Su trabajo fue social y político, pues contribuyeron en la organizaron de los campesinos en la lucha por la tierra y en la modernización del campo; además, participaron en las comunidades para evitar enfermedades y combatir vicios; en una palabra, para construir al "hombre nuevo" que México necesitaba. En los años veinte, el francés Jean Charlot y la aguascalentense Anita Brenner hablaron de un "renacimiento cultural", y el poeta Ramón López Velarde escribió: "El país se renueva ante los estragos".

MHS: ¿Está de acuerdo que sin comprender el proceso de la Revolución Mexicana no se puede entender el siglo XX en ninguno de sus aspectos? En este sentido, ¿cuál fue la aportación de este movimiento para configurar el Sistema Educativo Mexicano?

SCS: No creo que para entender el siglo XX mexicano tengamos siempre que referirnos a la revolución, pero sí en algunos aspectos, como el educativo, para bien y para mal, pues los resultados no siempre fueron los que se esperaban. El centralismo de nuestro Sistema Educativo inició con la idea de que los estados y municipios no eran capaces de hacer las reformas necesarias. En un país en caos después de una prolongada guerra, había razón para pensar y actuar así, pero después no. Jaime Torres Bodet ya a mediados del siglo XX criticaba ese centralismo educativo que ahora padecemos. Por el otro lado, el proyecto educativo posrevolucionario fue positivo en cuanto puso al Estado como principal responsable de impulsar una educación para todos. Ahora, debemos ser críticos y propositivos, porque hay más posibilidades para que, por lo menos, la población tenga su educación básica, pero la enseñanza en las escuelas, desde educación básica a superior, sigue siendo deficiente. En este sentido, la calidad educativa en México es uno de los grandes retos del gobierno y particularmente de la sociedad civil. Creo que falta aquel ímpetu posrevolucionario para lograrlo. 